\title{
Duration Of Delayed Graft Function And Its Impact On Graft Outcomes In Deceased Donor Kidney Transplantation Running Head: Impact of Duration of Delayed Graft Function
}

Pooja Budhiraja ( $\sim$ budhiraja.pooja@mayo.edu )

Mayo Clinic

Kunam S Reddy

Mayo Clinic

Richard J Butterfield

Mayo Clinic

Caroline C Jadlowiec

Mayo Clinic

Adyr A Moss

Mayo Clinic

Hassan A Khamash

Mayo Clinic

Lavanya Kodali

Mayo Clinic

Suman S Misra

Mayo Clinic

Raymond L Heilman

Mayo Clinic

\section{Research Article}

Keywords: kidney transplant, deceased donor, delayed graft function

Posted Date: February 9th, 2022

DOl: https://doi.org/10.21203/rs.3.rs-1277907/v1

License: (c) (i) This work is licensed under a Creative Commons Attribution 4.0 International License.

Read Full License 


\section{Abstract}

Background. There is controversy regarding the impact of delayed graft function (DGF) on kidney transplant outcomes. We hypothesize that the duration of DGF, rather than DGF itself, is associated with long-term kidney graft function.

Methods. We analyzed all deceased donor kidney transplants (DDKT) done at our center between 2008 to 2020 with DGF to determine factors associated with DGF duration as well as the impact of DGF duration on 1) acute rejection, BKV infection, progression of fibrosis on protocol biopsy, and death censored graft survival 2) resource utilization, including hospital length of stay and readmissions. DGF duration was assessed at three 14-day intervals: <14 DGF days, 14-27 DGF days, >28 DGF days.

Results. There were 1714 DDKT were included, 59.4\% ( $n=1018)$ had DGF. The median DGF duration was 10 days IQR $(6,15)$. The majority of recipients $(95 \%)$ had resolution of DGF within 28 days. Donor factors associated with DGF days were longer cold ischemia time, donor on inotropes, older age, donation after circulatory death, higher terminal creatinine, and hypertension. Recipient factors associated with increased DGF duration included male sex, length on dialysis before transplant, and higher body mass index. There were no differences in acute rejection events or interstitial fibrosis progression by 4 months when comparing DGF days. The median length of stay was 3 days. However, readmissions increased with increasing DGF duration. Death-censored graft survival was not associated with the length of DGF except when DGF lasted $>28$ days.

Conclusions. Inferior graft survival was observed only in recipients of DDKT with DGF lasting beyond 28 days. DGF lasting $<28$ days had no impact on graft survival. Duration of DGF, rather than DGF itself, is associated with graft survival.

\section{Trial Registration. Retrospective study approved by Mayo Clinic IRB.}

\section{Background}

The incidence of delayed graft function (DGF) after kidney transplantation has increased substantially over time, as a result of increased utilization of kidneys from high Kidney Donor Profile Index (KDPI) donors, acute kidney injury (AKI) donors, donation after circulatory death (DCD) donors and broader geographic allocation (national sharing). $(1,2)$ DGF has historically been associated with inferior graft survival. (3-7) Although high KDPI, AKI, and DCD kidneys are at a higher risk for DGF, there are differences in the kidney allograft survival between the subgroups, with DCD and AKI donors having excellent outcomes. $(8,9,10)$

DGF has increased resource utilization and concern for poor outcomes, including rejection and worse graft survival. (3-7) However, the data supporting poor outcomes associated with DGF, including rejection and graft survival, remains inconclusive. Some studies suggest decreased graft survival $(4,5)$, which may be related to a higher rate of rejection $(6,7,11)$; others have not found an association between DGF and 
acute rejection or graft survival. (12) Delayed graft function is often multifactorial and related to a combination of the donor, transplant, and recipient factors. Other reasons for these differing results may be due to the reporting of DGF as a dichotomous outcome rather than a continuum, different study populations, and center practices.

A few registry-based studies have assessed the impact of DGF duration on graft survival rates. $(13,14) \mathrm{A}$ United Kingdom (UK) registry-based study reported that DGF duration $>14$ days (13) was associated with an increased risk of death-censored graft failure. In contrast, an Australian study found a direct timedependent effect between DGF duration and graft loss. (14) In the United States, although the Scientific Registry of Transplant Recipients database assesses kidney transplant outcomes and reports DGF, it does not provide data specific to DGF days.

We analyzed a large cohort of patients with DGF to determine factors associated with DGF duration as well as the impact of DGF duration on 1) acute rejection, BKV infection, progression of interstitial fibrosis and death-censored graft survival, and 2) resource utilization, including hospital length of stay and readmissions.

\section{Methods}

This is a single-center retrospective study of patients receiving deceased donor kidney transplantation (DDKT) from 2008 to 2020. This study was approved by the Mayo Clinic Institutional Review Board. The last follow-up was at the end of November 2020.

Delayed graft function was defined as the recipient needing dialysis during the first 7 days posttransplant. The last dialysis day was used as the end of DGF. Delayed graft function duration was assessed at three 14-day intervals: <14 DGF days, 14-27 DGF days, >28 DGF days. Patients who received multi-organ transplants, preemptive transplants $(n=326)$, living donor kidney transplants $(n=1028)$, and those who had early graft failure within 10 days due to vascular complications were excluded $(n=18)$. Primary nonfunction (PNF) was included in the group with DGF days $>28$ and was defined as needing dialysis for $>90$ days and no recovery of graft function.

Donor AKI was classified per creatinine change as noted in the Acute Kidney Injury Network (AKIN) classification system. (15) At our center, as previously published, we accept kidneys based on kidney biopsy findings. $(8,16)$ Availability of machine perfusion and pump perfusion parameters do not play a role in decisions regarding kidney utilizations. $(8,16)$ Donor warm ischemia time was calculated from donor asystole time (time from withdrawal of support to aortic cross-clamp and perfusion with cold preservation fluid).

Protocol post-reperfusion (time-zero) and surveillance biopsies were performed at 4 months posttransplantation. For-cause biopsies were done in the setting of persistent DGF beyond 2 weeks or for concern for rejection. All rejection episodes were confirmed by biopsy. Subclinical rejection episodes on protocol biopsies were included in the analysis. The biopsies were classified using Banff criteria. (17) We 
calculated the acute rejection by 4 months, including any for cause and protocol biopsy performed by 4 months. Progression of chronic interstitial fibrosis (ci) scoring was done using Banff scores and was defined as an increase in ci score by 1 or more from the baseline biopsy done post-implantation. BKV infection is diagnosed by BKV viremia, and BKV counts are checked monthly for the first 4 months and then at $6,8,12$ months, and annually percenters protocol.

All patients received induction therapy. Before 2011, patients received rabbit-anti thymocyte globulin. After 2011, induction was with alemtuzumab. Patients over age 65 received basiliximab, which did not change during the study period. Patients receiving induction with the depleting agents had complete withdrawal of corticosteroids by post-transplant day 5 , while maintenance corticosteroids were continued for those receiving basiliximab induction. Steroids were maintained if recipients had a panel reactive antibody $>80 \%$, donor-specific antibodies, or end-stage renal disease from glomerulonephritis.

Maintenance immunosuppression was with tacrolimus and mycophenolate mofetil. Tacrolimus was started on post-transplant days $0-1$, irrespective of DGF. Goals for trough tacrolimus levels were 8-10 $\mathrm{ng} / \mathrm{mL}$ for the first month and then $6-8 \mathrm{ng} / \mathrm{mL}$. Recipients were discharged from the hospital by day 2 to 4 , irrespective of DGF, and monitored in the outpatient setting. Patients with ongoing delayed function 2 weeks post-transplant underwent repeat Doppler ultrasound imaging and allograft biopsy.

\section{Statistical Analysis}

Descriptive statistics were reported as mean (standard deviation) or median, interquartile range (IQR) for continuous variables, and frequency (percentage) for categorical variables. We compared donor and recipient-related variables between patients with and without DGF in the entire cohort using the Equal Variance t-test for continuous variables and the Chi-Square test for categorical variables. Nonparametric Kruskal Wallis tests compared data that were heavily skewed.

In the cohort with DGF, the number of DGF days as a continuous variable was modeled using multivariable linear regression with variable inclusion based on univariate significance at $p<0.05$ level and clinical significance. We also divided DGF into 3 groups of 14-day intervals to better characterize the effect of DGF days. We used the above cutoff as previous studies have reported the effect of DGF after 14 days. (13) Here, recipient and donor characteristics were compared by DGF day groups using Analysis of variance (ANOVA) or Chi-Sq, where appropriate. We tested different cutoff points for the duration of DGF using the Contal and O'Quigley method. (18) Primary nonfunction were not included in the Contal and O'Quigley calculation.

Our primary outcome was to study the effect of DGF days on death censored graft survival. We used the unadjusted Kaplan Meier method to estimate death censored graft survival between 14-day groups of DGF days. We performed Kaplan Meier with and without PNF cases. We used the adjusted Cox Proportional Hazard model when considering DGF days as a continuous variable in the subgroup of patients with DGF for death censored Graft survival analysis. 
We compared the incidence of acute rejection, the occurrence of BKV infection, progression of interstitial fibrosis (from preimplantation to 4 months), length of stay, and readmissions at 30 and 90 -days posttransplant in the DGF groups.

All statistical analyses were two-sided and considered statistically significant at the $p=0.05$ level. Analyses were performed in SAS v9.4 (SAS Institute; Cary, NC).

\section{Results}

There were 1018 (59\%) recipients with DGF and 696 (41\%) without DGF. The majority of patients had resolution of DGF by 14 days $(n=749,74 \%)$, while $21 \%(n=217)$ had resolution of DGF between $15-28$ days and $5 \%(n=52)$ had DGF lasting $>28$ days. The median duration of dialysis days in the DGF group was $10(6,15)$.

Baseline recipient and donor characteristics are shown in Table 1. With an increasing number of DGF days, it was more common to see kidney allografts coming from donors with hypertention, a higher KDPI score, DCD status, and AKI. Similarly, an increase in cold ischemia time (CIT) was associated with a longer DGF duration. (Table 1)

\section{Death Censored Graft Survival}

Overall, death-censored graft survival (log-rank P-value=0.302) was similar between the DGF and no DGF groups (Figure 1a, Log-rank $\mathrm{p}=0.57$ ). When we tested different cutoff points for the duration of DGF using the Contal and O'Quigley Method, 28 days of DGF was identified as the significant cutoff point where the hazard ratio was $3.813(p<0.001)$. Kaplan-Meier graft survival in the 3 subgroups of DGF compared to no DGF groups is shown in Figure 1b. Delayed graft function $>28$ days (log-rank $p<0.001$ ) was associated with inferior graft survival. After excluding PNF, DGF >28 days was associated with increased death censored graft survival (log-rank $\mathrm{p}<0.001)$.

On multivariate analysis, Cox proportional hazard model DGF $>28$ days was associated with higher death censored graft failure [2.85 (1.3-6.1), $\mathrm{P}=0.008$ ]. (Table 2) Delayed graft function duration, when used as a continuous variable for the group with $<28$ days of DGF, it was not associated with graft loss $(p=0.783)$. (Table 2) An increase in KDPI score was associated with increased hazards of graft loss $\{1.013$ (1.011.02), $p=0.001\}$. (Table 2 )

Increasing recipient age (1.039-1.071), $\mathrm{p}<0.001$ and male sex (1.19-2.36), $\mathrm{p}=0.003$ and not DGF days $(0.99-1.02, p=0.59)$ was associated with decreased recipient survival.

\section{Acute Rejection and BKV Infection}


The rate of acute rejection, including subclinical rejection within 4 months and the rate of BK infection within the first year, was similar between the groups (Table 3 ).

\section{Chronic Interstitial Fibrosis Progression}

Chronic interstitial fibrosis (ci) progression at 4 months was similar in the no DGF and DGF groups $(p=0.45)$ (Table 3). Delayed graft function days $(p=0.21)$ were not associated with ci progression at 4 months on logistic regression. Table 3 shows ci scores at times 0 and 4 months. In the group with DGF $>28$ days, only $40 \%$ (21) subjects had renal biopsy available at times 0 and 4 months for comparison.

\section{Length of Stay and Readmission in 30 and 90 Days (Table 3)}

The median length of stay was 3 days for all the groups. Readmissions within 30 days were $26 \%$ in no DGF, $36 \%$ in DGF $\leq 14$ days and around $50 \%$ for DGF $>14$ days (Table 3 ). Readmissions in 90 days increased with the duration of DGF. Thirty-four percent in no DGF group, $46 \%$ in DGF $<14$ days, $61 \%$ is DGF $15-28$ days and $64 \%$ in DGF lasting $>28$ days $(p<0.001)$.

\section{Risk Factors for DGF (Table 4)}

Multivariate analysis of donor and recipient factors associated with the duration of DGF days is shown in Table 4. Donor factors associated with DGF duration were longer CIT (0.19), donor on inotropes (1.2), older age (0.03), donation after circulatory death (3.3), higher terminal creatinine (0.96), and hypertension (1.3). Recipient factors associated with DGF duration included male sex (1.7), pretransplant dialysis days (0.001), and higher body mass index (0.11).

\section{Subgroup Analysis of DGF Duration > 28 Days}

On univariate analysis, a higher KDPI score [62(21) vs. 53.2(25), $p=0.013$ ] and donor HTN (44\% vs. $29 \%$, $p=0.04$ ) were more commonly observed in patients with DGF lasting $>28$ days compared to $\leq 28$ days (Table for supplement). Post-transplant recipient factors contributing to prolonged DGF included infection $(n=6)$, cardiovascular-related complications $(n=7)$, cirrhosis-related decompensation $(n=1)$, acute rejection $(n=2)$, reoccurrence of focal segmental glomerulosclerosis $(n=2)$, hemolytic uremic syndrome $(n=1)$, fibrin thrombi and later sepsis $(n=1)$ and post-transplant bleeding $(n=3)$.

Ten patients needed dialysis for 90 or more days. Of these 7 were declared PNF: 1 recipient received a standard KDPI kidney and had acute cellular rejection and pyelonephritis; 1 recipient received an AKI and high KDPI kidney; 2 recipients had chronic hypotension due to cardiac causes; 1 recipient had hypotension due to cirrhosis; 2 recipients had graft loss likely related to advanced chronic changes on 
time-0 biopsy (ah1, cg0, ci2-3, ct2-3, cv2-3); and a seventh recipient received an AKI kidney and had hypotension and focal segmental glomerulosclerosis recurrence post-transplant.

Three recipients came off dialysis after being dialyzed for 90 days. One needed dialysis for 6 months due to post-transplant thrombotic microangiopathy with cortical necrosis but came off dialysis and has had satisfactory graft function for more than 4 years. This patient received a kidney from a young donor with a KDPI score $<20 \%$. Two subjects had chronic changes on biopsy and maintained graft function after being switched to belatacept.

\section{Discussion}

The true impact of DGF on kidney transplant outcomes remains debated, and in most studies, DGF is reported as a dichotomous outcome rather than a continuum. During this study period, we assessed 1714 DDKT of which, $59 \%(n=1018)$ had DGF. We observed a median DGF duration of 10 days, with the majority of recipients (95\%) showing resolution of DGF within 28 days. There were no differences in acute rejection events or interstitial fibrosis progression by 4 months when comparing DGF days. Readmissions increased with increasing DGF duration. Death-censored graft survival was not associated with the length of DGF except when DGF lasted $>28$ days. To our knowledge, this is the first study to examine in detail the effect of DGF duration on rejection, readmissions, graft survival, and histology using a large cohort of deceased donor kidneys with DGF.

In a UK single center (7) study with DCD donors from 2011 to 2016, the presence of DGF was associated with lower graft survival, though the duration of DGF was not. In contrast, a UK registry-based DCD study (13) reported that DGF $>14$ days was associated with an increased risk of death-censored graft failure (hazard ratio $1 \cdot 7, p=\cdot 001$ ) and recipient death (hazard ratio $1 \cdot 8, p<001$ ) compared to grafts with immediate function. (13) That study reported a 2.5 times higher incidence of acute rejection within 3 months in recipients with DGF lasting $>14$ days than those with DGF duration $<7$ days. Because this was a registry-based study, there was insufficient data on induction and maintenance immunosuppression and if transplant centers held tacrolimus in the setting of DGF.

Authors Lim et al., using the Australian and New Zealand Dialysis and Transplant Registry, reported a direct effect between DGF duration and death-censored graft loss. (14) The authors reported DGF > 7 days was associated with a greater than $40 \%$ risk of graft loss. They also reported an association between DGF duration and risk for acute rejection [1.17 (1.10-1.25; $p<0.001)$ ]; subjects who developed acute rejection at 6 months were more likely to have graft loss. Although this reported association is worrisome, it is important to note that the study had a higher incidence of acute rejection, $30 \%$ risk at 6 months, greater than expected. The lower use of T-cell depleting induction (3.5\% with DGF vs. $10.7 \%$ without DGF) may have contributed to this finding. (14) In our present study, DGF days did not negatively impact death-censored graft survival except for those patients with DGF duration $>28$ days. Duration of DGF also had no impact on acute rejection as compared to the registry-based studies mentioned above. By comparison, depleting agents were used in $70 \%$ of our recipients with DGF. By protocol, our center also 
does not modify induction or delay initiation of calcineurin inhibitors in the setting of DGF. Our center's practice of early tacrolimus initiation combined with higher levels $(8-10 \mathrm{ng} / \mathrm{ml})$ within the first month of the transplant could be reasons for these observed differences in early rejection.

Despite some data suggesting otherwise, there continue to be concerns in the transplant community regarding the impact of DGF on the progression of allograft interstitial fibrosis. (21) We have previously demonstrated that DGF does not increase the risk for interstitial fibrosis at one year. (19) In the current study, we studied the effect of DGF duration on the risk of interstitial fibrosis progression. We did not find any significant impact of DGF days on the progression of chronic interstitial fibrosis compared to time 0 post-reperfusion biopsies to 4 months protocol.

Our center aims to discharge patients on post-transplant days 2-3 irrespective of DGF. As we have previously reported, our center's protocol is to routinely discharge patients with outpatient non-hospital based hemodialysis and close follow-up in our outpatient transplant clinic to minimize hospital length of stay. The median length of stay was 3 days, irrespective of DGF days. We observed higher readmission rates at 30 and 90 days, with increasing DGF duration. Compared to those without DGF, recipients with DGF lasting >14 days had a 22-24\% higher 30-day readmission rate and $27-30 \%$ higher 90 -day readmission rate.

Unlike previously published studies $(13,14)$, death-censored graft survival was not associated with the length of DGF except when DGF lasted $>28$ days. Graft loss in patients with DGF lasting $>28$ days was often due to a combination of donor and recipient factors. Recipient factors contributing to the graft loss identified in our study included cardiovascular complications, severe infections, acute rejection, and glomerulonephritis. For these recipients, prolonged DGF and associated outcomes appeared to be secondary to these post-transplant events.

\section{Conclusions}

Our study is a single-center study and has several limitations. As a center that utilizes a high proportion of high KDPI, AKI, DCD, and nationally allocated kidneys, our overall incidence of DGF is higher than other centers. As a result, we recognize that our experience with DGF and outcomes may be unique compared to the greater transplant community. Although we assessed hospital length of stay and readmission rates, the financial impact of DGF duration was not assessed in detail. Access to outpatient non-hospitalbased hemodialysis is a practice specific to our center that has helped us decrease inpatient hospital resource utilization. This unique aspect of our practice may not be universally applicable to other centers as resource availability varies from center to center. Despite these limitations, we feel that our experience with DGF and outcomes are valuable. Despite using donors with higher risk features and overall higher rates of DGF, we have reported excellent outcomes. $(8,9,16,19,20)$ Moreover, this current study provides granular details specific to DGF that are not available from larger database studies.

We conclude that the duration of DGF, rather than DGF itself, has greater clinical significance and is associated with kidney transplant outcomes. Delayed graft function lasting up to 28 days post-transplant 
for most patients has no detrimental impact on graft survival. However, DGF persisting for $>28$ days is associated with inferior kidney graft survival. When assessed in the context of therapeutic and timely immunosuppression, increasing duration of DGF does not increase the risk of acute rejection or progression of interstitial fibrosis. Although DGF is associated with higher readmission rates, long-term outcomes remain excellent. Future studies assessing the impact of DGF on kidney transplant outcomes should consider transitioning from the assessment of DGF as a dichotomous outcome to that of a continuum.

\section{Abbreviations}

AKI Acute Kidney Injury

AKINAcute Kidney Injury Network

ANOVA Analysis of variance

ci Chronic Interstitial Fibrosis

CIT Cold Ischemia Time

DCD Donation after Circulatory Death

DDKTDeceased Donor Kidney Transplantation

DGF Delayed Graft Function

HTN hypertension

IQR Interquartile Range

KDPIKidney Donor Profile Index

PNF Primary Nonfunction

UK United Kingdom

\section{Declarations}

Declarations (see instructions here: https://bmcnephrol.biomedcentral.com/submissionguidelines/preparing-your-manuscript/research-article)

\section{Ethics approval and consent to participate:}


The Mayo Clinic Institutional Review Board granted an exemption from requiring ethics approval on the ground that these analyses are conducted on de-identified data. The Mayo Clinic Institutional Review Board granted an exemption for written informed consent for this study. The study was carried out in accordance with the Declaration of Helsinki

\section{Consent for publication:}

Not applicable.

\section{Availablity of data and materials:}

The datasets generated and/or analysed during the current study are not publicly available due [these are sensitive data] but are available from the corresponding author on reasonable request.

\section{Competing interests:}

none

\section{Funding:}

none

\section{Authors' contributions:}

Raymond L Heilman and Pooja Budhiraja conceived the study. Pooja Budhiraja, Raymond L Heilman, Richard J Butterfield and Caroline $\mathrm{C}$ Jadlowiec participated in research design, writing of the article, performing the research, and data analysis. All authors participated in the preparation of the manuscript and agreed to the submitted version of the paper.

\section{Acknowledgements:}

not applicable

\section{References}

1. Irish WD, Ilsley JN, Schnitzler MA, Feng S, Brennan DC. A risk prediction model for delayed graft function in the current era of deceased donor renal transplantation. Am J Transplant 2010; 10: 227986. 
2. Heilman RL, Khamash HA, Huskey JL, Chakkera HA, Batra RK, Katariya NN, et al. Kidney transplant program at the Mayo Clinic in Arizona. Clin Transpl 2014; 61-8.

3. Hagenmeyer EG, Haussler B, Hempel E, Grannas G, Kalo A, Kilburg, et al. Resource use and treatment costs after kidney transplantation: impact of demographic factors, comorbidities, and complications. Transplantation 2004; 77: 1545-50.

4. Chen R, Wang H, Song L, Hou J, Peng J, Dai H, et al. Predictors and one-year outcomes of patients with delayed graft function after deceased donor kidney transplantation. BMC Nephrol 2020; $21: 526$.

5. Zens TJ, Danobeitia JS, Leverson G, Chlebeck PJ, Zitur LJ, Redfield RR, et al. The impact of kidney donor profile index on delayed graft function and transplant outcomes: A single-center analysis. Clin Transplant 2018; 32: e13190.

6. Jayaram D, Kommareddi M, Sung RS, Luan FL. Delayed graft function requiring more than one-time dialysis treatment is associated with inferior clinical outcomes. Clin Transplant 2012; 26: E536-43.

7. Shamali A, Kassimatis T, Phillips BL, Burton H, Kessaris N, Callaghan C. Duration of delayed graft function and outcomes after kidney transplantation from controlled donation after circulatory death donors: a retrospective study. Transpl Int 2019; 32: 635-45.

8. Jadlowiec CC, Heilman RL, Smith ML, Khamash HA, Huskey JL, Harbell J, et al. Transplanting kidneys from donation after cardiac death donors with acute kidney injury. Am J Transplant 2020; 20: 864-9.

9. Budhiraja P, Heilman RL, Jadlowiec CC, Smith ML, Ryan MS, Khamash HA, et al. Successful outcomes with transplanting kidneys from deceased donors with acute kidney injury on temporary renal replacement therapy. Clin Transplant 2021; 35: e14465.

10. Le Dinh H, Weekers L, Bonvoisin C, Krzesinski JM, Monard J, de Roover A, et al. Delayed graft function does not harm the future of donation-after-cardiac death in kidney transplantation. Transplant Proc 2012; 44: 2795-802.

11. Troppmann C, Gillingham KJ, Gruessner RW, Dunn DL, Payne We, Najarian JS, et al. Delayed graft function in the absence of rejection has no long-term impact. A study of cadaver kidney recipients with good graft function at 1 year after transplantation. Transplantation 1996; 61: 1331-7.

12. de Kok MJ, McGuinness D, Shiels PG, de Vries DK, Tutein Nolthenius JB, Wijermars LG, et al. The neglectable impact of delayed graft function on long-term graft durvival in kidneys donated after circulatory death associates with superior organ resilience. Ann Surg 2019; 270: 877-83.

13. Phillips BL, Ibrahim M, Greenhall GHB, Mumford L, Dorling A, Callaghan CJ. Effect of delayed graft function on longer-term outcomes after kidney transplantation from donation after circulatory death donors in the United Kingdom: A national cohort study. Am J Transplant 2021; 21:3346-55.

14. Lim WH, Johnson DW, Teixeira-Pinto A, Wong G. Association between duration of delayed graft function, acute rejection, and allograft outcome after deceased donor kidney transplantation. Transplantation 2019; 103: 412-9.

15. Mehta RL, Kellum JA, Shah SV, Molitoris BA, Ronco C, Warnock DG, et al. Acute Kidney Injury Network: report of an initiative to improve outcomes in acute kidney injury. Crit Care 2007; 11: R31. 
16. Heilman RL, Smith ML, Reddy KS. Utilization of kidneys with acute kidney injury in the extended criteria donor setting. Am J Transplant 2015; 15: 2783.

17. Solez K, Colvin RB, Racusen LC, Haas M, Sis B, Mengel M, et al. Banff 07 classification of renal allograft pathology: updates and future directions. Am J Transplant 2008; 8: 753-60.

18. O'Quigley J, Pepe M, Fisher L. Continual reassessment method: a practical design for phase 1 clinical trials in cancer. Biometrics 1990; 46: 33-48.

19. Heilman RL, Smith ML, Smith BH, Qaqish I, Khamash H, Singer AL, et al. Progression of interstitial fibrosis during the first year after deceased donor kidney transplantation among patients with and without delayed graft function. Clin J Am Soc Nephrol 2016; 11: 2225-32.

20. Jadlowiec CC, Hanna WA, Ninan J, Ryan MS, Das DM, Smith M, et al. Transplant outcomes using kidneys from high KDPI acute kidney injury donors. Clin Transplant 2021; 35: e14279.

\section{Tables}

\section{Table 1}

\section{Comparison of Groups Based on Delayed Graft Function (DGF) Days}




\begin{tabular}{|c|c|c|c|c|c|}
\hline & No DGF & DGF days & & & P \\
\hline & $0(n=696)$ & $\leq 14(n=749)$ & $15-28(n=217)$ & $>28(n=52)$ & \\
\hline $\begin{array}{l}\text { Donor age } \\
\text { (years) }\end{array}$ & $36.9(19.1)$ & $40(15.6)$ & $41.5(14.8)$ & $46(12)$ & $<0.001$ \\
\hline Male & $425(61 \%)$ & $463(62 \%)$ & $146(66.4 \%)$ & $19(47.5 \%)$ & 0.135 \\
\hline $\begin{array}{l}\text { Donor Body } \\
\text { mass index } \\
\left(\mathrm{kg} / \mathrm{m}^{2}\right)\end{array}$ & 26.7 (7.4) & $29.9(7.8)$ & $29.6(7.6)$ & $30(10.5)$ & $<0.001$ \\
\hline $\begin{array}{l}\text { Donor } \\
\text { Hypertension }\end{array}$ & $161(24.2 \%)$ & 209 (29\%) & $62(29 \%)$ & $22(46 \%)$ & 0.005 \\
\hline $\begin{array}{l}\text { Donor Black } \\
\text { race }\end{array}$ & $46(6.6 \%)$ & $62(8 \%)$ & $15(7 \%)$ & $2(4 \%)$ & 0.47 \\
\hline $\begin{array}{l}\text { Donor Acute } \\
\text { Kidney Injury } \\
\text { stage } \geq 2\end{array}$ & 94 (13.5\%) & $385(51 \%)$ & $130(60 \%)$ & $20(39 \%)$ & $<0.001$ \\
\hline KDPI & $46.6(28.9)$ & $52.7(24.7)$ & $54.8(25.1)$ & $62(21)$ & $<0.001$ \\
\hline $\mathrm{KDPI} \geq 85$ & $104(15 \%)$ & $92(12 \%)$ & $32(15 \%)$ & $9(17 \%)$ & 0.5 \\
\hline $\begin{array}{l}\text { Donation after } \\
\text { circulatory death }\end{array}$ & $106(15.2 \%)$ & 196(26\%) & $59(27 \%)$ & $20(39 \%)$ & $<0.001$ \\
\hline $\begin{array}{l}\text { Donor on } \\
\text { inotropes }\end{array}$ & $213(30.6 \%)$ & $243(32 \%)$ & $78(36 \%)$ & $15(38 \%)$ & 0.43 \\
\hline $\begin{array}{l}\text { Donor Diabetes } \\
\text { mellitus }\end{array}$ & $69(10.1 \%)$ & $57(7.8 \%)$ & $16(7.4 \%)$ & $6(12 \%)$ & 0.31 \\
\hline $\begin{array}{l}\text { Donor terminal } \\
\text { creatinine } \\
(\mathrm{mg} / \mathrm{dl})\end{array}$ & $1.27(1.39)$ & $3.1(2.8)$ & $3.6(2.9)$ & $2.5(2.3)$ & $<0.001$ \\
\hline $\begin{array}{l}\text { Cold Ischemia } \\
\text { time }>24 \text { hours }\end{array}$ & $125(18 \%)$ & $247(33 \%)$ & $68(31 \%)$ & $22(42 \%)$ & $<0.001$ \\
\hline $\begin{array}{l}\text { Cold Ischemia } \\
\text { time (hours) }\end{array}$ & $16.9(7.3)$ & $20.8(6.7)$ & $21.4(6.2)$ & $21.7(8)$ & $<0.001$ \\
\hline Pumped kidney & $60(9 \%)$ & $92(12 \%)$ & $21(10 \%)$ & $8(15 \%)$ & 0.4 \\
\hline $\begin{array}{l}\text { Warm ischemia } \\
\text { time (minutes) }\end{array}$ & $28.11(12)$ & $24.8(10)$ & $29(11)$ & $21(6.8)$ & 0.32 \\
\hline Recipient Male & $351(50.4 \%)$ & $482(64 \%)$ & $145(66 \%)$ & $32(76 \%)$ & $<0.001$ \\
\hline $\begin{array}{l}\text { Recipient Black } \\
\text { race }\end{array}$ & $68(9.8 \%)$ & $93(12.4 \%)$ & $31(14.3 \%)$ & $5(9.6 \%)$ & 0.21 \\
\hline Recipient Age at & $54.4(14.0)$ & $56.1(13)$ & $56.5(12)$ & $56.8(12)$ & 0.04 \\
\hline
\end{tabular}




\begin{tabular}{|c|c|c|c|c|c|}
\hline $\begin{array}{l}\text { Recipient Body } \\
\text { mass index } \\
\left(\mathrm{kg} / \mathrm{m}^{2}\right)\end{array}$ & $28.1(5.6)$ & $29.1(5.6)$ & $29.9(5.8)$ & $31.2(5.5)$ & $<0.001$ \\
\hline $\begin{array}{l}\text { Recipient Length } \\
\text { on Dialysis } \\
\text { (days) }\end{array}$ & $1306.2(1042)$ & 1365.3(942) & 1504(895) & $1540(850)$ & 0.04 \\
\hline $\begin{array}{l}\text { Pretransplant } \\
\text { Diabetes } \\
\text { mellitus }\end{array}$ & $250(35.9 \%)$ & $347(46 \%)$ & $120(55 \%)$ & $28(54 \%)$ & $<0.001$ \\
\hline $\begin{array}{l}\text { Previous } \\
\text { transplant }\end{array}$ & $87(12.5 \%)$ & $69(9.2 \%)$ & $21(9.5 \%)$ & $5(9.6 \%)$ & 0.21 \\
\hline $\begin{array}{l}\text { Panel reactive } \\
\text { antibody (\%) }\end{array}$ & 21.91(35.5) & $17.8(32.4)$ & 18.7(31.6) & $16.5(29.5)$ & 0.11 \\
\hline Induction & & & & & $<0.001$ \\
\hline & $\begin{array}{l}\text { Basiliximab- } \\
165(25 \%)\end{array}$ & $\begin{array}{l}\text { Basiliximab- } \\
203(29 \%)\end{array}$ & $\begin{array}{l}\text { Basiliximab- } \\
60(29 \%)\end{array}$ & $\begin{array}{l}\text { Basiliximab- } \\
15(33 \%)\end{array}$ & \\
\hline \multicolumn{6}{|l|}{$\begin{array}{l}\text { Rabbit-anti } \\
\text { thymocyte } \\
\text { globulin }\end{array}$} \\
\hline \multirow[t]{2}{*}{ Alemtuzumab } & $\begin{array}{l}\text { Rabbit-anti } \\
\text { thymocyte } \\
\text { globulin } \\
-139(21 \%)\end{array}$ & $\begin{array}{l}\text { Rabbit-anti } \\
\text { thymocyte } \\
\text { globulin }-87 \\
(12 \%)\end{array}$ & $\begin{array}{l}\text { Rabbit-anti } \\
\text { thymocyte } \\
\text { globulin } \\
-26(13 \%)\end{array}$ & $\begin{array}{l}\text { Rabbit-anti } \\
\text { thymocyte } \\
\text { globulin } \\
-6(13 \%)\end{array}$ & \\
\hline & $\begin{array}{l}\text { Alemtuzumab- } \\
355(54 \%)\end{array}$ & $\begin{array}{l}\text { Alemtuzumab- } \\
418(59 \%)\end{array}$ & $\begin{array}{l}\text { Alemtuzumab- } \\
120(59 \%)\end{array}$ & $\begin{array}{l}\text { Alemtuzumab- } \\
26(54 \%)\end{array}$ & \\
\hline
\end{tabular}

Continuous variables given as mean (standard deviation); categorical variables given as frequency (percentage)

Table 2

\section{Death Censored Graft Survival}


Univariate

\begin{tabular}{|c|c|c|c|c|c|}
\hline Variable & Level & $\mathrm{HR}(95 \% \mathrm{Cl})$ & $\begin{array}{l}\mathrm{P}- \\
\text { value }\end{array}$ & $\begin{array}{l}\mathrm{HR}(95 \% \\
\mathrm{Cl})\end{array}$ & $\begin{array}{l}P \text { - } \\
\text { value }\end{array}$ \\
\hline Delayed function & Yes vs. No & $\begin{array}{l}0.83(0.59 \\
1.12)\end{array}$ & 0.30 & & \\
\hline $\begin{array}{l}\text { DGF (more than or less than } \\
28 \text { days) }\end{array}$ & $\begin{array}{l}>28 \text { days } v s \leq \\
28 \text { days }\end{array}$ & $3.3(1.55-7.14)$ & 0.002 & $\begin{array}{l}2.85(1.3- \\
6.1)\end{array}$ & 0.008 \\
\hline $\begin{array}{l}\text { Days of DGF for those with } \\
\text { DGF }<28 \text { days }\end{array}$ & $\begin{array}{l}\text { One day } \\
\text { Increase }\end{array}$ & $\begin{array}{l}0.99(0.97- \\
1.02)\end{array}$ & 0.783 & & \\
\hline Age at Transplant & $\begin{array}{l}\text { One Unit } \\
\text { Increase }\end{array}$ & $\begin{array}{l}0.99(0.97 \\
1.004)\end{array}$ & 0.16 & & \\
\hline Recipient Sex & Male vs. female & $\begin{array}{l}1.12(0.79 \\
1.16)\end{array}$ & 0.59 & & \\
\hline Recipient Race & Black vs. White & $1.56(0.9,2.5)$ & 0.055 & $\begin{array}{l}1.61(1.01 \\
2.58)\end{array}$ & 0.05 \\
\hline $\begin{array}{l}\text { Recipient Body mass index } \\
\left(\mathrm{kg} / \mathrm{m}^{2}\right)\end{array}$ & $\begin{array}{l}\text { One Unit } \\
\text { Increase }\end{array}$ & $\begin{array}{l}1.01(0.98 \\
1.04)\end{array}$ & 0.66 & & \\
\hline $\begin{array}{l}\text { Recipient pre transplant } \\
\text { Diabetes mellitus }\end{array}$ & Yes vs. No & $\begin{array}{l}1.13(0.82 \\
1.56)\end{array}$ & 0.46 & & \\
\hline Previous Kidney Transplant & Yes vs. No & $\begin{array}{l}1.093(0.66 \\
1.82)\end{array}$ & 0.73 & & \\
\hline Length Dialysis (days) & $\begin{array}{l}\text { One Unit } \\
\text { Increase }\end{array}$ & $\begin{array}{l}1.002(0.997 \\
1.01)\end{array}$ & 0.39 & & \\
\hline $\begin{array}{l}\text { Donor Acute Kidney Injury } \\
(>1=2)\end{array}$ & Yes vs. No & $\begin{array}{l}0.94(0.67 \\
1.33)\end{array}$ & 0.74 & & \\
\hline Kidney Donor Profile Index & $\begin{array}{l}\text { One Unit } \\
\text { Increase }\end{array}$ & $\begin{array}{l}1.01(1.002, \\
1.015)\end{array}$ & 0.01 & $\begin{array}{l}1.013 \\
(1.01-1.02)\end{array}$ & 0.001 \\
\hline Cold Ischemia Time (hours) & $\begin{array}{l}\text { One Unit } \\
\text { Increase }\end{array}$ & $\begin{array}{l}1.013(0.99 \\
1.04)\end{array}$ & 0.29 & & \\
\hline $\begin{array}{l}\text { Warm Ischemia Time } \\
\text { (minutes) }\end{array}$ & $\begin{array}{l}\text { One Unit } \\
\text { Increase }\end{array}$ & $1.02(0.96,1.09)$ & 0.55 & & \\
\hline Panel of Reactive Antibody (\%) & $\begin{array}{l}\text { One Unit } \\
\text { Increase }\end{array}$ & $1.00(0.99,1.01)$ & 0.59 & & \\
\hline $\begin{array}{l}\text { Histocompatibility Antigen } \\
\text { mismatches }\end{array}$ & One increase & $1.09(0.97,1.22)$ & 0.15 & & \\
\hline
\end{tabular}


Acute Rejection and BKV and Length of Stay

Page 16/20 


\begin{tabular}{|c|c|c|c|c|c|}
\hline & No DGF & DGF days & & & \\
\hline & $0(n=696)$ & $\begin{array}{l}<14 \\
(n=749)\end{array}$ & $\begin{array}{l}15-28 \\
(n=217)\end{array}$ & $\begin{array}{l}>28 \\
(n=52)\end{array}$ & $\begin{array}{l}P \\
\text { value }\end{array}$ \\
\hline $\begin{array}{l}\text { Acute rejection including } \\
\text { subclinical rejection within } 4 \\
\text { months of transplant }\end{array}$ & $79(11.4 \%)$ & $68(9.1 \%)$ & $25(11.4 \%)$ & $10(19 \%)$ & 0.09 \\
\hline $\begin{array}{l}\text { BKV infection within } 1 \text { year of } \\
\text { transplant }\end{array}$ & $116(16.7 \%)$ & $106(14.2 \%)$ & $31(14.3 \%)$ & $4(7.7 \%)$ & 0.24 \\
\hline $\begin{array}{l}\text { Length of stay (days) } \\
\text { (Median) }\end{array}$ & $3(2,4)$ & $3(2,4)$ & $3(2,4)$ & $3(2,5)$ & \\
\hline Readmission at 30 days & $178(26 \%)$ & $266(36 \%)$ & $108(50 \%)$ & $25(48 \%)$ & $<0.001$ \\
\hline Readmission at 90 days & $239(34 \%)$ & $346(46 \%)$ & $132(61 \%)$ & $32(64 \%)$ & $<0.001$ \\
\hline Pathology & $0(n=696)$ & $\begin{array}{l}\leq 14 \\
(n=749)\end{array}$ & $\begin{array}{l}15-28 \\
(n=217)\end{array}$ & $\begin{array}{l}>28 \\
(\mathrm{n}=52)\end{array}$ & \\
\hline \multicolumn{6}{|l|}{ Ci progression at 4 month $(+2)$} \\
\hline Missing & 372 & 334 & 108 & 36 & \\
\hline Yes & 154 & 200 & 64 & 14 & 0.196 \\
\hline No & 170 & 215 & 45 & 12 & \\
\hline ci score at time 0 (time 0 ci score) & & & & & $<0.001$ \\
\hline Missing & $274(39 \%)$ & $223(30 \%)$ & $70(32 \%)$ & $21(40 \%)$ & \\
\hline ciO & $342(49 \%)$ & $393(53 \%)$ & $108(49 \%)$ & $20(39 \%)$ & \\
\hline ci1 & $77(11 \%)$ & $126(17 \%)$ & $41(19 \%)$ & $10(20 \%)$ & \\
\hline $\mathrm{ci}>1$ & $3(0.4 \%)$ & $7(0.9 \%)$ & $1(0.5 \%)$ & $1(2 \%)$ & \\
\hline Ci score at 4 month & & & & & $<0.001$ \\
\hline missing & $199(29 \%)$ & $179(24 \%)$ & $64(29 \%)$ & $23(44 \%)^{\star}$ & \\
\hline $\mathrm{c} 0$ & $231(33 \%)$ & $200(27 \%)$ & $40(18 \%)$ & $8(15 \%)$ & \\
\hline c1 & $228(33 \%)$ & $314(42 \%)$ & 95 (43\%) & $12(23 \%)$ & \\
\hline
\end{tabular}


Ci chronic interstitial fibrosis

*ci at 4 months was not available in $44 \%$ of subjects with DGF $>28$ days. Continuous variables given as mean (standard deviation); categorical variables given as number (percentage)

\section{Table 4}

\section{Predictors of DGF Days}




\begin{tabular}{|c|c|c|c|c|}
\hline & Univariate & & Multivariable & \\
\hline Variable & Estimate (SE) & P-value & Estimate (SE) & P-value \\
\hline Recipient Age at Transplant & $0.05(0.02)$ & 0.02 & $-0.19(0.02)$ & 0.3 \\
\hline Recipient sex (male vs female) & $2.3(0.4)$ & $<0.001$ & $1.7(0.4)$ & $<.001$ \\
\hline Recipient Race (Black vs White) & $0.82(0.9)$ & 0.34 & & \\
\hline Recipient body mass index $\left(\mathrm{kg} / \mathrm{m}^{2}\right)$ & $0.24(0.05)$ & $<0.001$ & $0.11(0.04)$ & 0.004 \\
\hline Diabetes Pretransplant Diabetes mellitus & $2.6(0.54)$ & $<.0001$ & $0.64(0.4)$ & 0.15 \\
\hline Previous Kidney Transplant & $-0.366(0.8)$ & 0.68 & & \\
\hline Length Dialysis (days) & $0.02(0.01)$ & 0.02 & $0.001(0.01)$ & 0.02 \\
\hline Donor Acute Kidney Injury $\geq 2$ & $5.23(0.376)$ & $<.0001$ & & \\
\hline Kidney Donor Profile Index & $0.05(0.01)$ & $<0.001$ & & \\
\hline Cold ischemia Time (hours) & $0.3(0.04)$ & $<0.001$ & $0.19(0.03)$ & $<.001$ \\
\hline Donor Hypertension & $2.1(0.6)(0.437)$ & 0.001 & $1.3(0.5)$ & 0.01 \\
\hline Donor Oliguria/Anuria & $5.0(0.5)$ & $<.001$ & & \\
\hline Donor age & $0.06(0.02)$ & $<.001$ & $0.03(0.01)$ & 0.03 \\
\hline Donor Sex (male vs female) & $0.12(0.4)$ & 0.7 & & \\
\hline Donor Race (Black vs. White) & $-0.2(1.4)$ & 0.88 & $-1.5(0.8)$ & 0.08 \\
\hline Donor body mass index $\left(\mathrm{kg} / \mathrm{m}^{2}\right)$ & $0.16(0.04)$ & $<0.001$ & $0.02(0.03)$ & 0.48 \\
\hline Donation after Circulatory Death & $2.8(0.6)$ & $<.001$ & $3.3(0.5)$ & $<.001$ \\
\hline Donor Diabetes Mellitus & $-0.765(0.68)$ & 0.26 & & \\
\hline Panel Reactive Antibody (\%) & $-0.01(0.1)$ & 0.23 & & \\
\hline Warm Ischemia Time (minutes) & $-0.08(0.08)$ & 0.29 & & \\
\hline Donor on inotropes & $1.05(0.4)$ & 0.02 & $1.2(0.4)$ & 0.01 \\
\hline Terminal donor creatinine $(\mathrm{mg} / \mathrm{dl})$ & $0.98(0.1)$ & $<.0001$ & $0.96(0.08)$ & $<0.001$ \\
\hline
\end{tabular}

\section{Figures}

Figure 1 
Legend not included with this version

\section{Supplementary Files}

This is a list of supplementary files associated with this preprint. Click to download.

- supplementtable.docx 